\title{
A Discussion on the Ways to Improve Pupil Well-being
}

\author{
Zeyang Yang1, a , Lingyu Liü, b,* \\ ${ }^{1}$ Department of Education, University of York, York, YO105DD, UK \\ ${ }^{2}$ School of Foreign Languages, Wuhan Polytechnic University, Wuhan, 430023, China \\ azy664@york.ac.uk, b498753088@qq.com
}

Keywords: Well-being, pupil, literature review

\begin{abstract}
As the topic of mental health has become increasingly popular recently in education, psychology and several other social science disciplines, well-being of young students has raised great concerns worldwide. This paper aims to explore the ways to improve pupil well-being by reviewing literatures. The first part describes the definition of pupil well-being and a theoretical model. Then a number of empirical studies on pupil well-being focusing on schools, teachers, social relationship and pupils themselves were reviewed. According to the definition, theoretical model and the empirical evidence, the ways of improving pupil well-being are discussed in the final parts of discussion and conclusion.
\end{abstract}

\section{Introduction}

"Happiness matters." [1] Happier people are more likely to learn from outside and have better self-fulfilment [1]. Not only for the adults, pupil's well-being is positively related to their development [2]. Meanwhile, it is the wish of every parent that their children can enjoy their lives as well-being is the common target of every person [1]. Therefore, the well-being of the school children or the pupils can be an issue which needs to be highlighted. However, the Good Childhood Report shows that the well-being drops off as the children grow from the age of 8 to 16 and 17 [3]. A study found that 20 percent of the pupils who are 8 to 10 years old had low levels of well-being [4]. Although the percentage of unhappy students is not high, the potential number of that population still seems to be non-ignorable. As education is the "intervention in pupil's life" [5], schools and teachers may be the major issues when considering the ways to improve the pupil well-being. Meanwhile, the factors out of school may also affect pupils' well-being and the effectiveness of the measures of improving pupil well-being remains unclear [6]. Accordingly, there might be an argument that the ways to improve pupil well-being can be associated with several integrated factors. The aim of this paper is discussing the ways to improve pupil well-being based on theories and empirical studies.

\section{Definition and Theory of Pupil Well-Being}

\subsection{Defining Pupil Well-Being.}

The definitions of "well-being" given by dictionaries have several points in common. The Collins dictionary: 175 years of dictionary publishing gives the definition of "well-being" as the "the condition of being contended, healthy, or successful; welfare." [7]. While the Longman dictionary of English language and culture define "well-being" as "personal and physical comfort, especially good health and happiness." [8]. In those definitions, well-being is associated with the meanings of contention, health, success, welfare, happiness and comfort. Those terms describing well-being are relevant to the good or positive feelings of people. The term "pupil" is defined as "a person, especially a child who is being taught." [8], or "a student who is taught by a teacher, esp. a young student." [7]. It is obvious that the term "pupil" is directly related to the term "teacher". While children's well-being is also relevant to the contexts [9]. Therefore, when considering improving 
pupil well-being, the positive feelings of the school children related to the teachers and school conditions are the key point of discussion.

\subsection{The Student Well-Being Model (SWBM).}

The student well-being model (SWBM) is a conceptual framework developed by a group of researchers in New Zealand [2]. During their one-year longitudinal study, observations of classes, interviews and other ways of data collection were conducted in a high school in New Zealand. They concluded seven aspects of pupil well-being: having, being, relating, relating, feeling, thinking, functioning and striving [2]. Then a theoretical model was formed combing the seven components based on their research. The SWBM includes a wide range of multi-disciplinary themes related to pupil well-being including teacher quality, school environment, student-teacher relationships, students' emotions etc. This model indicate the potential factors linked with pupil well-being.

\section{Empirical Studies on Pupil Well-Being}

\subsection{School Transition and Pupil Well-Being.}

A study investigated the relationship between primary-secondary school transition and the pupil well-being [10]. The longitudinal study was conducted from 1996 to 2003 among 2000 Scottish students from 11 to 19 who experienced the transition from primary school to secondary school. The transition includes peer transition and school transition. By comparing the students of different ages, it was found that the poor transition from primary school to secondary school predicted negative outcomes such as lower levels of self-esteem, stronger feelings of depression and greater anxiety. Those effects related to well-being may even continuously negatively affect the student in the later years while the age of pupils makes a difference either.

This study shows that successful school transition among pupils is essential to their well-being. However, it still seems ambiguous to simply identify poor school transition as a reason of low level of well-being. The researchers point out that the size of school, timetable, bullying, new teachers and new friends are all obvious factors related to the students' difficulties [10]. Therefore, more specific studies on those detailed factors like school conditions, peer relationship and teachers may be effective for a better understanding of the key issues about pupil well-being.

\subsection{School Environment and Pupil Well-Being.}

A study concentrated on whether smaller classes make students happier [11]. The study was conducted among 2755 pupils from 159 classes of 40 schools in Sweden aiming at finding the relationship between class size and pupil well-being. The findings indicate that class size had no strong effect on pupil well-being and mental health problems. However, this study only focused on one aspect of school environment which is the class size. It seems that school environment may be more complex while the conditions of settings on campus or even the interpersonal relationship can be part of the school environment.

A study investigated pupils' well-being and school environment among 18 students from a primary school in the UK [12]. Those students were divided into four focus groups. During the semi-structured group interviews, they were asked about the impact of school environment on their mental health and well-being. The researcher reported that outside areas, toys, toilets near the classroom and clean dinner table made the pupils feel happy and satisfied, while food on the floor, untidy toilets and limited space of playground were negatively affected their well-being. Furthermore, the pupils in the study also reported that the kind help from the others and the use of humour were positive factors to their sense of happiness. Meanwhile, social participation in school activities as well as the clubs is another positive factor to their good feeling. Therefore, the "school environment" investigated in this study can be understood from two perspectives, the visible school settings and invisible interpersonal environment. The conditions of basic school settings like the dining room, the toilet and the playground had positive effect on pupils' well-being. However, the invisible 
environment around the pupils seems to be related to other factors like the school activities and the relationship between teachers and pupils.

\subsection{School Activities and Pupil Well-Being.}

To investigate students' pedagogical well-being, a study was conducted among 518 pupils in six comprehensive and secondary schools in Finland [13]. The pupils were investigated by a survey of open-ended questions covering four aspects, the importance of school experience, their interaction with teachers, the developments of their schools and their troublesome experience on their ways to schools. The findings show that the pupils' well-being was related to their relationship with their classmates as well as their teachers. Furthermore, the pupils' experience of participation in school teaching activities and informal after-class activities were relevant to their well-being. The researchers concluded that both learning outcomes and experiences of social interactions are the key elements of pupil well-being [13].

Another study explored the relationship between music and pupil well-being [14]. As a music teacher of a primary school in the UK, the researcher conducted a voluntary discussion with 5 pupils in the school choir. The students in the conversation showed their feelings of happiness, confidence and achievement after the experiences in the school choir. The involved pupils forgot their unpleasant things, developed new friendships and simply felt better through singing. Thus, music especially singing may be positive to pupil well-being as music can contribute something to the pupils' lives. However, music may also be related to the other factors like school activities and course design. Maybe, music related activities or music lessons can be effective in improving pupil well-being.

However, pupil individual differences also need to be considered when discussing pupils' experiences of activities. In the Finnish study, girls were more likely to focus interpersonal interactions while boys tended to focus more on success and failure of performances. Meanwhile, girls found more support from peers than boys while they reported more stress or anxiety from peers more than boys. Different students may benefit from experiences in activities in different ways [13]. Some students felt happier with negative experiences while some gained benefits from positive experiences. Consequently, it is still hard to conclude that school activities are all positive to improving pupil well-being. For example, a chance to sing a song in public might be welfare for one pupil and a nightmare for another.

\subsection{Teachers’ Responsibilities for Pupil Well-Being.}

In order to investigate teachers' responsibilities for pupil well-being, a study re-analysed the interviews conducted among a group of Swedish teachers [5]. The teachers' responsibilities were understood in two directions, the social given responsibility related to laws or norms, and the responsibility related to personal moral issues. However, the two responsibilities cannot be discussed separately as the researchers argue that the teachers' responsibilities can be a mix of given and felt responsibilities according to the interviews. The findings show that teaching pupils well for their well-being was a duty of the teachers, and the characters of teachers were indispensable [5].

According to the definitions discussed in previous section, the term "pupil" is directly related to the term "teacher". Thus, it is no doubt that pupil well-being is related to teachers [5]. Consequently, for the ways of improving pupil well-being, the teachers' relationship with pupils become a key issue again as the study about class size reviewed previously also discusses about teacher-and-pupil relationship. Therefore, since well-being refers to the feelings of happy and comfortable, the teachers' responsibilities for pupil well-being can be thought as how teachers develop good relationship with pupils and make pupils feel happy.

\subsection{Consumerism and Pupil Well-Being.}

To investigate the relationship between consumerism and pupil well-being, a study was conducted among 2934 adolescences in seven Scottish secondary schools [15]. The term "consumerism” was interpreted as the trust that goods can lead to happiness. The pupils in the study were year one to year three of secondary schools from urban and rural areas. Questionnaires and group discussions were 
used in the study. They found that the students' dissatisfaction of their family support on their shopping activities was associated with poorer well-being. The attitudes towards brand were different between boys and girls. The awareness of brand improved the boys' well-being and reduced the girls' well-being. Furthermore, maintaining status among peers was another factor associated with well-being found in this study.

The results of this study draw the focus on the factors of pupil character differences and peer relationship. According to the study, having or not having something might have no impact on pupil well-being at all. Meanwhile, what make pupils happy may not be the goods but the comments from their friends. Consequently, when considering the ways to improve pupil well-being, these two factors can also be considered. However, apart from the two factors focused, it remains unclear whether schools, teachers and parents have impact on pupils' views of consumerism. If the guidance of schools, teachers and parents have great effect on pupils' views of their possessions, the negative effect of consumerism may be avoided through school activities or teachers' instructions.

\subsection{Health, Safety and Family Problems Effects on Pupil Well-Being.}

A number of current studies focused on the effects of health, safety and family problems on pupil. A group of researchers supplied food from local donation to the pupils who suffered from food shortage before [16]. Those pupils' achievement in schools was improved after their intervention. Meanwhile, another study found that bullying in schools negatively affected the pupils' involvement in school activities and learning process [17]. Furthermore, family situations of divorced parents and separated parents had negative impact on pupils' learning and even their dropping out of schools [18]. Overall, health, safety and family problems were proved to be related to the students' learning and engagement in activities in those studies. As learning achievement and involvement in activities are key factors of pupil well-being [9], health, safety and family problems are relevant factors to pupil well-being that teachers, schools and the society should consider seriously.

\section{Discussion on the Ways of Improving Pupil Well-Being}

For the ways of improving pupil well-being, the factors discussed in the definitions, theoretical and empirical research evidence suggest several possible perspectives: children's emotions, school conditions, social relationships, teachers, family problems etc. The Good Childhood Report points out there are six priorities for children's well-being including self, environment, leisure, relationships, money and learning which are deeply related to the factors discussed above [3]. Consequently, thinking through the factors discussed above, the ways of improving pupil well-being can be concluded in five directions including the pupils themselves, the parents, the teachers, the school leaders and the society.

Firstly, pupils need to understand that they can improve their well-being through their own efforts. In order to guide pupils to improve well-being by themselves, researchers suggested Human Given (HG) therapy which was proved as an effective way to improve pupil well-being [19]. The HG therapy gives pupils a course for forty-five minutes every week covering six main points, building relationships, collecting information, making plans, assessing personal achievements, setting strategies and taking actions. Furthermore, The Good Childhood Report gives five ways to improve well-being including connect, be active, learning, take notice, giving and creativity [3]. In short, the pupils are recommended to learn actively from the outside world, communicate with the others, be confident, be optimistic and live in an organised life style.

Secondly, parents have the responsibility to help pupils. The five ways of improving pupil well-being given above are also designed for the parents [3]. Therefore, the parents' job is taking care of their children' growth and guiding them to live and learn in a positive way as discussed in the five ways. Meanwhile, parents need to understand the importance of suitable possessions of their children. They may guide their children how to manage money and keep right attitude to their possible peer pressure.

Thirdly, teachers take the key responsibility for pupils. According to the discussions above, their 
relationship with pupil may affect the pupil well-being deeply. Kyriacou argues that pupils will learn better in a classroom atmosphere based on good teacher-student relationship while teachers and pupils respect each other and stay in harmony [20]. Therefore, to improving pupil well-bring, teachers need to develop good relationship with pupils and make them feel happy.

Fourthly, the school leaders also have the responsibility for improving pupil well-being. As discussed previously, the fundamental school settings, the organization of school activities have impact on pupil well-being. Therefore, the school leaders' job is maintaining their existing positive settings and beneficial activities for students. Furthermore, schools may take the responsibility to help and encourage pupils take part in school activities but taking care of the student differences. While bullying may be another key problem the schools should consider [3]. Another point is the relationship between schools and parents. Good relationship between parents and head teachers of schools can have positive effect on pupil well-being [4]. Therefore, the schools and parents need to contact with each other and take the responsibility together.

Fifthly, the society including the government and the social communities are recommended to be aware of pupil well-being. The Good Childhood Report states that both national and local policies can have influence on pupil well-being [3]. Thus, the government have the responsibility to take effective measures improve pupils' health condition and build a safe environment for pupils' lives. A service for children well-being called the Child Behaviour Intervention Initiative (CBII) was presented [21]. The CBII was set up in Leicester City of UK aiming at improving children mental health and well-being by proving ding support for individuals, families and identified groups. Therefore, both the government and the social groups can help pupils and make them have happier lives.

Furthermore, the factors like gender, age and character differences were also significant to pupil well-being $[10,13,15]$. Consequently, concerning how to improve pupil well-being through the five aspects, the age differences, gender differences and other individual differences should not be ignored.

\section{Conclusion}

In conclusion, improving pupil well-being can be understood as making pupils feel happier, grow up with safety and health. Five aspects may possibly be considered including pupils themselves, parents, teachers, schools and society. Firstly, students are recommended to learn more, communicate with the others better, keep confident and live in positive ways. Secondly, parents need to guide the children to learn and develop in a happy environment with good health and confidence. Thirdly, teachers should develop positive relationship with pupil in schools and make sure the pupils enjoy their school lives. Fourthly, schools have the responsibility to ensure their basic settings and activities on campus are suitable and effective in helping the students' development and well-being. Finally, the government and social groups have the responsibility to build a better social environment for children' well-being by setting up positive policies or effective social services. Meanwhile, the gender, age and character differences are also key issues which are worthy of special care.

\section{References}

[1] S. Scoffham, \& J. Barnes. Happiness matters: towards a pedagogy of happiness and well-being, The Curriculum Journal, 22(4) (2011) 535-548.

[2] A. K. Soutter, B. O'Steen, \& A. Gilmore. The student well-being model: a conceptual framework for the development of student well-being indicators. International Journal of Adolescence and Youth, (2013) 1-25.

[3] The Good Childhood Report (2013), Retrieved from http://www.childrenssociety.org.uk/well-being.

[4] L. Gutman, \& L. Feinstein. Children's well-being in primary school: Pupil and school effects. 
Centre for Research on the Wider Benefits of Learning, Institute of Education, University of London. (2008)

[5] S. Edling, \& A. Frelin. Doing good? Interpreting teachers' given and felt responsibilities for pupils' well-being in an age of measurement, Teachers and Teaching: theory and practice, 19(4) (2013) 419-432.

[6] J. Coleman. Well-being in schools: empirical measure, or politician's dream? Oxford Review of Education, 35(3) (2009) 281-292.

[7] Collins dictionary: 175 years of dictionary publishing. London: Collins. (2007).

[8] Longman dictionary of English language and culture. Harlow: Longman. (1998).

[9] A. I. Konu, T. P. Lintonen, \& V. J. Autio. Evaluation of Well-Being in Schools - A Multilevel Analysis of General Subjective Well-Being, School Effectiveness and School Improvement: An International Journal of Research, Policy and Practice, 13(2) (2002) 187-200.

[10] P. West, H. Sweeting, \& R. Young. Transition matters: pupils' experiences of the primary-secondary school transition in the West of Scotland and consequences for well-being and attainment, Research Papers in Education, 25(1) (2010) 21-50.

[11] N. Jakobsson, M. Persson, \& M. Svensson. Class-size effects on adolescents' mental health and well-being in Swedish schools, Education Economics, 21(3) (2013) 248-263.

[12] S. Hall. Supporting mental health and wellbeing at a whole-school level: listening to and acting upon children's views, Emotional and Behavioural Difficulties, 15(4) (2010) 323-339

[13] K. Pyhältö, T. Soini, \& J. Pietarinen. Pupils’ pedagogical well-being in comprehensive school—significant positive and negative school experiences of Finnish ninth graders. European Journal of Psychology of Education, 25(2) (2010) 207-221.

[14] R. Wills. The magic of music: a study into the promotion of children's well-being through singing, International Journal of Children's Spirituality, 16(1) (2011) 37-46.

[15] H. Sweeting, K. Hunt, \& A. Bhaskar. Consumerism and well-being in early adolescence, Journal of Youth Studies, 15(6) (2012) 802-820.

[16] S. Hipsky, D.Scigliano, \& D. Parker. Schools Leaders Successfully Partner With Community Organization Providing Nutrition So Students Focus on Learning Instead of on Hunger. Journal of Cases in Educational Leadership, 16(2) (2013) 54-60.

[17] S. B. Mehta, D. Cornell, X. Fan, \& A. Gregory. Bullying Climate and School Engagement in Ninth Grade Students. Journal of school health, 83(1) (2013) 45-52.

[18] C. Song, M. Benin, \& J. Glick. Dropping Out of High School: The Effects of Family Structure and Family Transitions. Journal of Divorce \& Remarriage, 53(1) (2012) 18-33.

[19] Y. Yates, \& C. Atkinson. Using Human Givens therapy to support the well-being of adolescents: a case example, Pastoral Care in Education: An International Journal of Personal, Social and Emotional Development, 29(1) (2011) 35-50.

[20] C. Kyriacou. Essential teaching skills (3rd ed.). Cheltenham: Nelson Thornes. (2007)

[21] J. Dawson, \& D. Singh-Dhesi. Educational psychology working to improve psychological well-being: an example, Emotional and Behavioural Difficulties, 15(4) (2010) 295-310. 